\title{
28 Resarch Soure Return to Work in the Gastric Cancer Survivors
}

\author{
Yuan-Yuei Chen \\ Tri-Service General Hospital \\ Wei-Liang Chen \\ Tri-Service General Hospital \\ Wei-Te Wu \\ National Health Research Institutes \\ Ching-Liang Ho \\ Tri-Service General Hospital \\ Chung-Ching Wang ( $\nabla$ bigching@gmail.com ) \\ Tri-Service General Hospital
}

\section{Research Article}

Keywords: gastric cancer, return to work, survival outcome

Posted Date: January 16th, 2021

DOI: https://doi.org/10.21203/rs.3.rs-144594/v1

License: (c) (i) This work is licensed under a Creative Commons Attribution 4.0 International License.

Read Full License 


\section{Abstract}

Returning to work (RTW) is an often used outcome in work research to describe employee fully recovering from disease. Several factors are suggested as barriers for workers returning to work. The goal of this study was to investigate the role of RTW in workers with gastric cancer and identify its impact on their survival outcomes during 11 years of follow-up. A total of 4467 workers who with newly diagnosis of gastric cancer were included in this retrospective cohort study with a follow-up period ranging from 2004 to 2015. Relationships between work, treatment, and disease-related variables and RTW were analyzed by Cox regression. The impact of RTW on survival outcomes was analyzed by Kaplan-Meier survival curves. Old age, males, comorbidities, chemotherapy, radiotherapy, and manual jobs were inversely associated with RTW. Operation and early stage of gastric cancer were associated with increased likelihood of RTW. After adjusting for variables, workers with stage 1 gastric cancer were more likely return to work than other stages with HR of 4.67 (95\% Cl: $2.99 \sim 7.31)$ and $7.44(95 \% \mathrm{Cl}: 4.12 \sim 13.43)$ in the $2^{\text {nd }}$ and $5^{\text {th }}$ year. In terms of effect of RTW on survival rate, reemployed workers had better survival than those without employment in all gastric cancer survivors. Furthermore, RTW had significant association with reduced risk of all-cause mortality (HR: $0.49,95 \% \mathrm{Cl}: 0.38 \sim 0.65)$. Improving these identified barriers and strengthening facilitators of RTW can provide employers and government to conduct comprehensive employment plans for increasing the percentage of RTW in the gastric cancer survivors.

\section{Introduction}

Despite a substantial decline in both incidence and mortality over the past decades, gastric cancer still remains an important public health burden worldwide. The incidence of gastric cancer is particularly higher in Eastern Asia than other districts in the world ${ }^{1}$. In Taiwan, gastric cancer was the sixth most common cancer in 1996 and the ranking dropped to ninth in $2016^{2}$. Gastric cancer is distinguished by the high variability of non-specific symptoms such as dyspepsia, weight loss and anemia, which makes early diagnosis difficult. Patients with gastric cancer have poor overall prognosis and quality of life ${ }^{3}$. As one of the leading causes of cancer-related mortality in worldwide ${ }^{4}$, gastric cancer was reported to exert a significant economic burden in Taiwan ${ }^{5}$.

After recovering from cancer, returning to work (RTW) is important to the survivors and their family and social roles as well as to their finances. Being employed is can reduce psychological distress and improve confidence and self-esteem ${ }^{6-8}$. However, most of cancer patients have suffered from physical and emotional problems such as pain, fatigue, anxiety, and depression after treatment which may lower their willingness of RTW ${ }^{9-11}$. Older age, education, comorbidity, advanced cancer stage, and treatment options are suggested as barriers for workers to return to work ${ }^{12}$. In a Korean study, patients with gastric cancer suffered from more difficulties in doing employment and housework than general population ${ }^{13}$. The goal of our cohort study was to explore relationships between RTW and disease, treatment, and work-related factors in workers with gastric cancer. Furthermore, we attempted to figure out whether the RTW had beneficial effect on survival outcomes on gastric cancer survivors or not. 


\section{Results}

\section{Characteristics of study sample}

Table 1 displayed work-, treatment-, and disease-related information of gastric cancer workers in RTW and non-RTW groups. A total of 1530 eligible workers (34.2\%) returned to work 5 years after the cancer diagnosis. The mean age of these two groups was $50.8 \pm 8.9$ and $52.9 \pm 10.2$ years at the 5 th year, respectively. The most common comorbidity was hypertension with 264 (17.2\%) and 589 (20.0\%) workers of the RTW group and non-RTW group. Most RTW workers received surgical treatment (37.7\%) after diagnosing with gastric cancer. In terms of work-related factors, the majority of businesses were located in the north Taiwan (51.7\%) for cancer survivors who returned to work. Most workers had income level less than 28800 New Taiwan Dollars (62.2\%). A large proportion of workers engaged in manufacturing jobs in both RTW (33.1\%) and non-RTW groups (30.6\%). Compared to the non-RTW group, most workers returning to work had early cancer stages in TNM staging system. There were 205 workers $(13.4 \%)$ who had stage 1 of gastric cancer returning to work. 
Table1. Demographic data of RTW group and non-RTW group

\section{Characteristic}

RTW

$(\mathrm{N}=1530)$

$\% \quad$ Non-RTW \%

$(\mathrm{N}=2937)$

\section{Age}

Mean age

$<45$

$45-52$

$>52$

Gender

Male

Comorbidities

Disorders of lipoid metabolism

Alcohol abuse

Hypertension

Myocardial infarction

Congestive heart failure

Peripheral vascular disease

Cerebrovascular disease

Dementia

Chronic pulmonary disease

Rheumatologic disease

Mild liver disease

Renal disease

Metastatic solid tumor

Psychoses

Depression

Treatment

Operation

Radiation therapy
$50.8 \pm 8.9$

383

468

679

773

$50.5 \quad 1749$

59.5

$52.9 \pm 10.2$

$25.0 \quad 632$

$30.6 \quad 773$

$44.4 \quad 1532$

52.2

26.3

10.1

156

$10.2 \quad 296$

1.2

15

$0.9 \quad 35$

20.0

264

$17.2 \quad 589$

0.4

7

$0.4 \quad 12$

1.9

23

$1.5 \quad 57$

0.7

12

$0.8 \quad 22$

2.6

36

$2.3 \quad 76$

0.3

5

0.39

5.4

63

$4.1 \quad 159$

0.8

13

$0.8 \quad 23$

11.3

173

$11.3 \quad 331$

2.3

20

$\begin{array}{ll}1.3 & 67\end{array}$

3.6

12

0.8106

0.7

8

$0.5 \quad 20$

1.9

$2.2 \quad 56$ 


\begin{tabular}{|c|c|c|c|c|}
\hline Chemotherapy & 230 & 15.0 & 834 & 28.4 \\
\hline \multicolumn{5}{|l|}{ Living area when diagnosed of cancer } \\
\hline Central & 300 & 19.6 & 540 & 18.4 \\
\hline North & 791 & 51.7 & 1634 & 55.6 \\
\hline East & 30 & 1.9 & 61 & 2.1 \\
\hline South + Islands & 409 & 26.7 & 702 & 23.9 \\
\hline \multicolumn{5}{|l|}{ Income range (TWD) } \\
\hline$<28800$ & 952 & 62.2 & 1707 & 58.1 \\
\hline $28800-38200$ & 265 & 17.3 & 452 & 15.4 \\
\hline$>38200$ & 313 & 20.4 & 778 & 26.5 \\
\hline \multicolumn{5}{|l|}{ Type of job } \\
\hline Agriculture, Forestry, and Animal Husbandry & 153 & 10.0 & 236 & 8.0 \\
\hline Manufacturing & 506 & 33.1 & 899 & 30.6 \\
\hline Electricity and Gas Supply & 8 & 0.5 & 11 & 0.4 \\
\hline Water Supply and Remediation Activities & 5 & 0.3 & 28 & 0.9 \\
\hline Construction & 175 & 11.4 & 341 & 11.6 \\
\hline Wholesale and Retail Trade & 184 & 12.0 & 345 & 11.7 \\
\hline Transportation and Storage & 97 & 6.3 & 211 & 7.2 \\
\hline Accommodation and Food Service Activities & 44 & 2.9 & 123 & 4.2 \\
\hline Information and Communication & 14 & 0.9 & 42 & 1.4 \\
\hline Financial and Insurance Activities & 37 & 2.4 & 77 & 2.6 \\
\hline Real Estate Activities & 14 & 0.9 & 25 & 0.8 \\
\hline Professional, Scientific and Technical Activities & 30 & 1.9 & 75 & 2.5 \\
\hline Support Service Activities & 40 & 2.6 & 103 & 3.5 \\
\hline Public Administration and Defense & 37 & 2.4 & 68 & 2.3 \\
\hline Education & 17 & 1.1 & 40 & 1.4 \\
\hline Human Health and Social Work Activities & 31 & 2.0 & 59 & 2.0 \\
\hline Amusement and Recreation Activities & 22 & 1.4 & 29 & 0.9 \\
\hline Other Service Activities & 116 & 7.6 & 225 & 7.7 \\
\hline
\end{tabular}




\begin{tabular}{|lllll|}
\hline Company size & & & & \\
\hline Shut down & 132 & 8.6 & 305 & 10.4 \\
\hline Small & 128 & 8.4 & 217 & 7.4 \\
\hline Large & 337 & 22.0 & 658 & 22.4 \\
\hline Pathological T stage & 933 & 60.9 & 1757 & 59.8 \\
\hline 1 & & & & \\
\hline 2 & 141 & 9.2 & 91 & 3.1 \\
\hline 3 & 106 & 6.9 & 116 & 3.9 \\
\hline 4 & 65 & 4.2 & 194 & 6.6 \\
\hline Pathological N stage & 27 & 1.8 & 145 & 4.9 \\
\hline 0 & & & & \\
\hline 1 & 233 & 15.2 & 178 & 6.1 \\
\hline 2 & 61 & 3.9 & 111 & 3.8 \\
\hline 3 & 27 & 1.8 & 119 & 4.0 \\
\hline Pathological M stage & 18 & 1.2 & 141 & 4.8 \\
\hline 0 & 62 & 4.0 & 101 & 3.4 \\
\hline 1 & 194 & 12.7 & 246 & 8.4 \\
\hline Pathological stage & 7 & 0.4 & 139 & 4.7 \\
\hline 1 & & & & 5.5 \\
\hline 2 & & 1.0 & 211 & 7.2 \\
\hline 4 & & & & \\
\hline
\end{tabular}

\section{Univariate analysis}

The unadjusted models of hazard ratios (HR) for RTW in 2nd and 5th year were listed in Fig. 1. Older workers who aged over 52 years were unlikely to return to work with HR of 0.79 (95\% Cl: $0.69 \sim 0.89)$. Males had less likelihood of RTW than females with HR of $0.85(95 \% \mathrm{Cl}: 0.78 \sim 0.92)$ and $0.77(95 \% \mathrm{Cl}$ : $0.69 \sim 0.85)$ in the 2 nd and 5 th year. Cancer survivors with comorbidities such as hypertension and 
metastatic solid tumor were unlikely to return to work with HR of $0.87(95 \% \mathrm{Cl}: 0.76 \sim 0.99)$ and 0.30 ( $95 \% \mathrm{Cl}: 0.17 \sim 0.53)$ in the 5th year. Patients who received surgical intervention had more likelihood to return to work with $\mathrm{HR}$ of 1.74 (95\% Cl: $1.50 \sim 2.02)$. In contrast, radiotherapy and chemotherapy were associated with decreased likelihood of RTW with HR of 0.68 ( $95 \% \mathrm{Cl}: 0.51 \sim 0.90)$ and 0.51 (95\% Cl: 0.44 $\sim 0.59$ ), respectively. The high-income group with salary over 38,800 New Taiwan Dollars was unlikely to return to work with HR of 0.74 ( $95 \% \mathrm{Cl}: 0.65 \sim 0.84)$ in the 5th year. In terms of the pathological stages of gastric cancer, workers who had earlier stage were more likely to return to work. T1 had higher likelihood of RTW than other stages with HR of 2.59 (95\% Cl: $1.88 \sim 3.55)$ and 3.92 ( $95 \% \mathrm{Cl}: 2.59 \sim 5.92)$ in the 2 nd and 5th year. N1 had higher likelihood of RTW than other stages with HR of $2.37(95 \% \mathrm{Cl}: 1.74 \sim 3.25)$ and 5.08 (95\% Cl: $3.14 ~ 8.21)$ in the 2nd and 5 th year. Workers with M0 were more likely to return to work with HR of 5.55 (95\% Cl: $3.35 ~ 9.21)$ and 8.76 (95\% Cl: $4.12 ~ 18.63)$ in the 2nd and 5th year. Workers diagnosed of stage 1 gastric cancer had higher likelihood of RTW than other stages with HR of 4.71 (95\%Cl: $3.33 \sim 6.66)$ and 9.05 (95\% Cl: $5.44 \sim 15.05$ ) in the 2 nd and 5th year.

\section{Multivariate analysis}

After fully adjusting for variables in Fig. 2, the relationships between cancer stages and RTW were remained significant. T1 had higher likelihood of RTW than other stages with HR of 2.16 (95\%Cl: 1.18 3.94) and 2.77 (95\% Cl: $1.27 ~ 6.06)$ in the 2nd and 5th year. N1 staging cancers had higher likelihood of RTW than other stages with HR of $2.24(95 \% \mathrm{Cl}: 1.25 \sim 4.01)$ and $3.53(95 \% \mathrm{Cl}: 1.53 \sim 8.14)$ in the 2nd and 5th year. M0 staging cancers were associated with an increased RTW with HR of 2.29 (95\%Cl: $1.29 \sim$ 4.08) and 2.31 ( $95 \% \mathrm{Cl}: 1.01 \sim 5.28$ ) in the 2 nd and 5th year. Workers diagnosed of stage 1 gastric cancer had higher likelihood of RTW than other stages with HR of $4.71(95 \% \mathrm{Cl}: 3.33 \sim 6.66)$ and $9.05(95 \% \mathrm{Cl}$ : $5.44 \sim 15.05)$ in the 2 nd and 5 th year. Like the same result of univariate analysis, stage 1 gastric cancer survivors were more likely to return to work with HR of 4.67 (95\% Cl: $2.99 \sim 7.31)$ and 7.44 (95\%Cl: 4.12 13.43) in the 2 nd and 5 th year.

\section{Survival outcome gastric cancer survivors}

Figure 3 displayed the survival rate of gastric cancer survivors in RTW and non-RTW group. In all gastric cancer survivors, reemployed workers had higher survival rate than those unemployed $(p<0.001)$. This relationship remained significant in workers with stage 3 and stage 4 gastric cancers $(p<0.001)$. In Table 2, the full adjustment model demonstrated that the likelihood of RTW was related to decreased risk of all-cause mortality with HR of $0.49(95 \% \mathrm{Cl}: 0.38 \sim 0.65)$. Collectively, our findings indicated that RTW might have benefits on survival outcomes of gastric cancer survivors. 
Table 2

Associations between the return to work and all-cause mortality

Unadjusted

$\mathrm{HR}(95 \% \mathrm{Cl})$
$P$ Value
Fully adjusted $\mathrm{HR}(95 \% \mathrm{Cl})$
$0.25(0.23,0.27)$
Return to work
$<0.001$
$0.49(0.38,0.65)$
$<0.001$

$0.25(0.23,0.27)$

$P$ Value

Adjusted covariates: age, treatment, income range, industrial classification, company size, cancer stage

\section{Discussion}

RTW can be considered as a crucial determinant of the quality of life for cancer survivors, especially because it is associated with a feeling of self-esteem, return to normal activity and sense of identity 11,14 . Most previous studies regarding employment status of cancer survivors focused on prostate and breast cancer, which are common in Europe ${ }^{15,16}$. To date, our study was the first to investigate the relationship between work, treatment, and disease-related factors and RTW in workers who are diagnosed of gastric cancers. Furthermore, we found the effects of RTW on survival outcomes of these cancer survivors.

Numerous studies have examined the association between employment status and cancer survivors. Bradley et al. demonstrated that patients with prostate cancer were less likely return to work than those without cancer ${ }^{16}$. Most head and neck cancer survivors returned to work within 6 months after treatment ${ }^{17}$. Compared to cancer free controls of similar age, breast cancer survivors show reduced work ability and higher unemployment ${ }^{18}$. Patients with a history of malignant brain tumors, colorectal, testicular and other cancers are reported lower work productivity, impaired physical activity and distressed mental status ${ }^{19,20}$. However, relationship between employment and RTW after treatment in workers with gastric cancer is rarely discussed in previous studies and still unknown. In a cross-sectional study, Lee et al. demonstrated that patients with gastric cancers had difficulties at work because they experienced more fatigue and had lower work capacity than general population ${ }^{13}$. The prevalence of depression was high in gastric cancer survivors and was related to increased risk of psychiatric morbidity 21,22 . According to previous studies, fatigue, exhaustion, anxiety, and depression are the potential barriers for cancer survivors making decision of RTW $23-25$.

Sociodemographic factors, treatment related factors, and work-related factors are reported to influence work ability and RTW decision of cancer survivors ${ }^{12,26,27}$. Older people are more likely to have sick leave and unemployment that lead to decreased likelihood of RTW ${ }^{28,29}$. In this cohort study, we observed that higher income was associated with decreased likelihood of RTW, which was differed from previous studies $^{30,31}$. Muijen et al. demonstrated that higher education and wage was associated with increased risk of work disability ${ }^{25}$. The result was consistent with our finding, however, the mechanism of high educated workers having less work participation should be investigated in future studies. In the present study, we observed that workers who underwent surgical treatment were more likely to return to work. In 
contrast, those who receive chemotherapy and radiotherapy are associated with reduced likelihood of RTW. The surgical intervention for tumor is the only possibility to cure a patient with early gastric cancer $^{32}$. In addition, most early stage cancer patients have less symptoms and better quality of life after operation that can return to work earlier ${ }^{33}$. Chemotherapy and radiotherapy are reported to be risk factors for cancer survivors not having RTW ${ }^{23,34}$. Side effects of chemotherapy such as depression, fatigue, and cognitive deficits contribute to the incapacity to work $^{35}$.

In this study, we represented that RTW might increase the survival rate of gastric cancer survivors compared those unemployed. Lee et al. displayed that Eastern Cooperation Oncology Group (ECOG) performance status was positively associated with work disability in gastric cancer survivors ${ }^{13}$.

Performance status, which is a quantification of cancer patients' general well-being and activities of daily life, has been used to evaluate survival outcome in many cancer types ${ }^{36}$. Several studied have reported that increased physical activity is significantly associated with reduced mortality ${ }^{37,38}$. Taken together, reemployed cancer survivors might have better survival rate than those without RTW because they had higher physical activity and lower fatigue that could maintain their quality of life.

There are several limitations in the study. First, we couldn't distinguish from the types of gastric cancer surgery which patients had in the present study. A previous study indicated that total gastrectomy was associated with increased risk of nonworking among gastric cancer survivors ${ }^{13}$. The prognosis may differ from different surgical procedures that influence patients' willingness of RTW. Second, educational level is considered as an important factor in employment ${ }^{39}$. However, the information of education was unavailable from the databases. Last, we couldn't collect the information about the motivation of RTW and job satisfaction in the study.

\section{Conclusion}

The decision of RTW is influenced by several aspects included treatment, work, and disease factors in gastric cancer survivors. Reemployed workers might have better survival than those unemployed due to improved mental status and increased physical activity. Better knowledge on barriers of RTW that cause physical and psychological impact on cancer survivors will promote the development of necessary interventions, incorporating shared health care, and occupational rehabilitation. Moreover, the effort can enhance and motivate the rate of RTW to a great extent.

\section{Methods}

\section{Data collection}

In this longitudinal study, we included 4467 Taiwanese workers who aged over 20 years with newly diagnosis of gastric cancer during the period 2004-2015. All characteristics were derived from three national population databases including the Labor Insurance Database (LID), the Taiwan Cancer Registry, 
and the National Health Insurance Research Database (NHIRD) from 2004 to 2015. Workers who met the exclusion criterias as follows were excluded from our study: diagnosed with more than 2 cancers, with metastatic solid tumors, ever diagnosed with gastric cancer before 2004, and younger than 20 years old. All of analytic procedures were conducted in accordance with the guidelines of Tri-Service General Hospital (TSGH).

\section{Diagnosis of gastric cancer}

The diagnosis of gastric cancer was based on the $\mathrm{NHI}$ catastrophic illness registry files the International Classification of Diseases, Ninth Revision, Clinical Modification (ICD-9-CM) codes. The ICD-9 CM codes of gastric cancers were listed in Supplementary Table 1. Patients who are newly diagnosed with gastric cancer must apply for catastrophic illness certification. After a strict verification which includes image reviews, pathological reports, and medical records by a panel of experts and specialists on the disease, the government would issue the certification.

\section{Study variables}

We collected employment-related data of gastric cancer survivors from the LID including age, gender, working district, company size, and income range. Clinical comorbidities were obtained from the NHIRD based on the corresponding ICD-9-CM codes and they were shown in Supplementary Table 2. Primary treatment such as operation, radiotherapy, chemotherapy, and pathological TNM stages of gastric cancer were also included in the analysis.

\section{Outcomes}

The 2nd and 5th year RTW of gastric cancer survivors were identified as the main outcome for this cohort study. Full RTW, which is defined as the time from sick leave to complete work resumption, was applied in the present study ${ }^{40}$. Because RTW was a pivotal indicator of recovery for oral cancer survivors, it was regarded as the primary endpoint in this cohort. To date, no previous studies have compared the survival rate between gastric cancer survivors in RTW and non-RTW group. We attempted to determine the survival outcome in different stages of gastric cancer as secondary endpoint to identify the effect of RTW on gastric cancer survivors. Moreover, the risk of all-cause mortality after workers returning to work within the follow-up was also analyzed in this cohort study.

\section{Statistical analysis}

All analyses in our study were applied by Statistical Package for the Social Sciences, version 22.0 (SPSS Inc., Chicago, IL, USA) for Windows. The period between the first day of sick-leave and complete reemployment was regarded as RTW. The period between diagnosis of gastric cancer and death was recorded as survival time from 2004 to 2015 . Cox regression analysis was conducted to predict the occurrence of RTW from a model including relevant variables. Hazard ratios (HR) produced by Cox regression analysis displaying the impacts of variables on the hazard of the RTW. The survival rates of 
gastric cancer survivors with or without RTW were analyzed using Kaplan-Meier survival curves categorized by different cancer stages.

\section{References}

1. Fitzmaurice, C. et al. Global, Regional, and National Cancer Incidence, Mortality, Years of Life Lost, Years Lived With Disability, and Disability-Adjusted Life-years for 32 Cancer Groups, 1990 to 2015: A Systematic Analysis for the Global Burden of Disease Study. JAMA oncology. 3, 524-548 https://doi.org/10.1001/jamaoncol.2016.5688 (2017).

2. Chang, J. S. et al. The Epidemiology of Gastric Cancers in the Era of Helicobacter pylori Eradication: A Nationwide Cancer Registry-Based Study in Taiwan. Cancer epidemiology, biomarkers \& prevention: a publication of the American Association for Cancer Research. cosponsored by the American Society of Preventive Oncology. 28, 1694-1703 https://doi.org/10.1158/1055-9965.Epi-190355 (2019).

3. Kaptein, A. A., Morita, S. \& Sakamoto, J. Quality of life in gastric cancer. World journal of gastroenterology. 11, 3189-3196 https://doi.org/10.3748/wjg.v11.i21.3189 (2005).

4. Bray, F. et al. Global cancer statistics 2018: GLOBOCAN estimates of incidence and mortality worldwide for 36 cancers in 185 countries. CA: a cancer journal for clinicians. 68, 394-424 https://doi.org/10.3322/caac.21492 (2018).

5. Hong, J. et al. The economic burden of advanced gastric cancer in Taiwan. BMC Health Serv Res. 17, 663-663 https://doi.org/10.1186/s12913-017-2609-1 (2017).

6. Slade, M. Mental illness and well-being: the central importance of positive psychology and recovery approaches. BMC Health Serv Res. 10, 26-26 https://doi.org/10.1186/1472-6963-10-26 (2010).

7. Chu, P. C., Chin, W. S., Guo, Y. L. \& Shiao, J. S. C. Long-Term Effects of Psychological Symptoms after Occupational Injury on Return to Work: A 6-Year Follow-Up. Int J Environ Res Public Health. 16, 235 https://doi.org/10.3390/ijerph16020235 (2019).

8. Black, C. Work, health and wellbeing. Saf Health Work. 3, 241-242 https://doi.org/10.5491/SHAW.2012.3.4.241 (2012).

9. Smith, T. et al. The rationale, design, and implementation of the American Cancer Society's studies of cancer survivors. Cancer. 109, 1-12 https://doi.org/10.1002/cncr.22387 (2007).

10. Bower, J. E. et al. Fatigue in long-term breast carcinoma survivors: a longitudinal investigation. Cancer. 106, 751-758 https://doi.org/10.1002/cncr.21671 (2006).

11. de Boer, A. G. E. M. et al. Work ability and return-to-work in cancer patients. Br J Cancer. 98, 13421347 https://doi.org/10.1038/sj.bjc.6604302 (2008).

12. Islam, T. et al. Factors associated with return to work of breast cancer survivors: a systematic review. BMC public health. 14 Suppl (3), https://doi.org/10.1186/1471-2458-14-s3-s8 (2014).

13. Lee, M. K. et al. Employment status and work-related difficulties in stomach cancer survivors compared with the general population. Br J Cancer. 98, 708-715 
https://doi.org/10.1038/sj.bjc.6604236 (2008).

14. Mehnert, A., de Boer, A. \& Feuerstein, M. Employment challenges for cancer survivors. Cancer. 119 Suppl (11), 2151-2159 https://doi.org/10.1002/cncr.28067 (2013).

15. Ullrich, A. et al. Return to work in prostate cancer survivors - findings from a prospective study on occupational reintegration following a cancer rehabilitation program. BMC cancer. 18, 751-751 https://doi.org/10.1186/s12885-018-4614-0 (2018).

16. Bradley, C. J., Neumark, D., Luo, Z., Bednarek, H. \& Schenk, M. Employment outcomes of men treated for prostate cancer. Journal of the National Cancer Institute. 97, 958-965 https://doi.org/10.1093/jnci/dji171 (2005).

17. Verdonck-de Leeuw, I. M., van Bleek, W. J., Leemans, C. R. \& de Bree, R. Employment and return to work in head and neck cancer survivors. Oral oncology. 46, 56-60 https://doi.org/10.1016/j.oraloncology.2009.11.001 (2010).

18. Cocchiara, R. A. et al. Returning to work after breast cancer: A systematic review of reviews. Work (Reading, Mass.). 61, 463-476 https://doi.org/10.3233/wor-182810 (2018).

19. Feuerstein, M., Hansen, J. A., Calvio, L. C., Johnson, L. \& Ronquillo, J. G. Work productivity in brain tumor survivors. Journal of occupational and environmental medicine. 49, 803-811 https://doi.org/10.1097/JOM.0b013e318095a458 (2007).

20. Yabroff, K. R., Lawrence, W. F., Clauser, S., Davis, W. W. \& Brown, M. L. Burden of illness in cancer survivors: findings from a population-based national sample. Journal of the National Cancer Institute. 96, 1322-1330 https://doi.org/10.1093/jnci/djh255 (2004).

21. et al. Factors Associated With Depression in Disease-Free Stomach Cancer Survivors. Journal of Pain and Symptom Management 46, 511-522, doi:10.1016/j.jpainsymman.2012.10.234 (2013).

22. Tavoli, A. et al. Anxiety and depression in patients with gastrointestinal cancer: does knowledge of cancer diagnosis matter?. BMC Gastroenterol. 7, 28-28 https://doi.org/10.1186/1471-230X-7-28 (2007).

23. Fantoni, S. Q. et al. Factors related to return to work by women with breast cancer in northern France. Journal of occupational rehabilitation. 20, 49-58 https://doi.org/10.1007/s10926-009-9215-y (2010).

24. Tiedtke, C., de Rijk, A., Donceel, P., Christiaens, M. R. \& de Casterle, B. D. Survived but feeling vulnerable and insecure: a qualitative study of the mental preparation for RTW after breast cancer treatment. BMC public health. 12, 538 https://doi.org/10.1186/1471-2458-12-538 (2012).

25. van Muijen, P., Duijts, S. F., Bonefaas-Groenewoud, K., van der Beek, A. J. \& Anema, J. R. Factors associated with work disability in employed cancer survivors at 24-month sick leave. BMC cancer. 14, 236 https://doi.org/10.1186/1471-2407-14-236 (2014).

26. Tan, F. L., Loh, S. Y., Su, T. T., Veloo, V. W. \& Ng, L. L. Return to work in multi-ethnic breast cancer survivors-a qualitative inquiry. Asian Pacific journal of cancer prevention: APJCP. 13, 5791-5797 https://doi.org/10.7314/apjcp.2012.13.11.5791 (2012). 
27. Mehnert, A. Employment and work-related issues in cancer survivors. Critical reviews in oncology/hematology 77, 109-130, doi:10.1016/j.critrevonc.2010.01.004 (2011).

28. Carlsen, K., Oksbjerg Dalton, S., Frederiksen, K., Diderichsen, F. \& Johansen, C. Cancer and the risk for taking early retirement pension: a Danish cohort study. Scandinavian journal of public health. 36 , 117-125 https://doi.org/10.1177/1403494807085192 (2008).

29. Drolet, M. et al. Not working 3 years after breast cancer: predictors in a population-based study. Journal of clinical oncology: official journal of the American Society of Clinical Oncology. 23, 83058312 https://doi.org/10.1200/jco.2005.09.500 (2005).

30. Ahn, E. et al. Impact of breast cancer diagnosis and treatment on work-related life and factors affecting them. Breast cancer research and treatment. 116, 609-616 https://doi.org/10.1007/s10549-008-0209-9 (2009).

31. Tamminga, S. J., de Boer, A. G., Verbeek, J. H. \& Frings-Dresen, M. H. Breast cancer survivors' views of factors that influence the return-to-work process-a qualitative study. Scandinavian journal of work, environment \& health. 38, 144-154 https://doi.org/10.5271/sjweh.3199 (2012).

32. Bollschweiler, E., Berlth, F., Baltin, C., Mönig, S. \& Hölscher, A. H. Treatment of early gastric cancer in the Western World. World journal of gastroenterology. 20, 5672-5678 https://doi.org/10.3748/wjg.v20.i19.5672 (2014).

33. Fan, H. G. et al. Fatigue, menopausal symptoms, and cognitive function in women after adjuvant chemotherapy for breast cancer: 1- and 2-year follow-up of a prospective controlled study. Journal of clinical oncology: official journal of the American Society of Clinical Oncology. 23, 8025-8032 https://doi.org/10.1200/jco.2005.01.6550 (2005).

34. Mols, F. \& van de Poll-Franse, L. V. Employment status among cancer survivors. Jama 302, 32-33; author reply 34-35, doi:10.1001/jama.2009.903 (2009).

35. Johnsson, A., Fornander, T., Rutqvist, L. E. \& Olsson, M. Factors influencing return to work: a narrative study of women treated for breast cancer. European journal of cancer care. 19, 317-323 https://doi.org/10.1111/j.1365-2354.2008.01043.x (2010).

36. Garcia, D. O. \& Thomson, C. A. Physical activity and cancer survivorship. Nutr Clin Pract. 29, 768-779 https://doi.org/10.1177/0884533614551969 (2014).

37. Ammitzbøll, G. et al. Physical activity and survival in breast cancer. European Journal of Cancer. 66, 67-74 https://doi.org/10.1016/j.ejca.2016.07.010 (2016).

38. Barbaric, M., Brooks, E., Moore, L. \& Cheifetz, O. Effects of physical activity on cancer survival: a systematic review. Physiother Can. 62, 25-34 https://doi.org/10.3138/physio.62.1.25 (2010).

39. Godges, J. J., Anger, M. A., Zimmerman, G. \& Delitto, A. Effects of education on return-to-work status for people with fear-avoidance beliefs and acute low back pain. Physical therapy. 88, 231-239 https://doi.org/10.2522/ptj.20050121 (2008).

40. Hoefsmit, N. et al. The Effectiveness of an Intervention to Enhance Cooperation Between Sick-Listed Employees and Their Supervisors (COSS). Journal of occupational rehabilitation. 26, 229-236 https://doi.org/10.1007/s10926-015-9606-1 (2016). 
Figures

$\mathbf{A}$

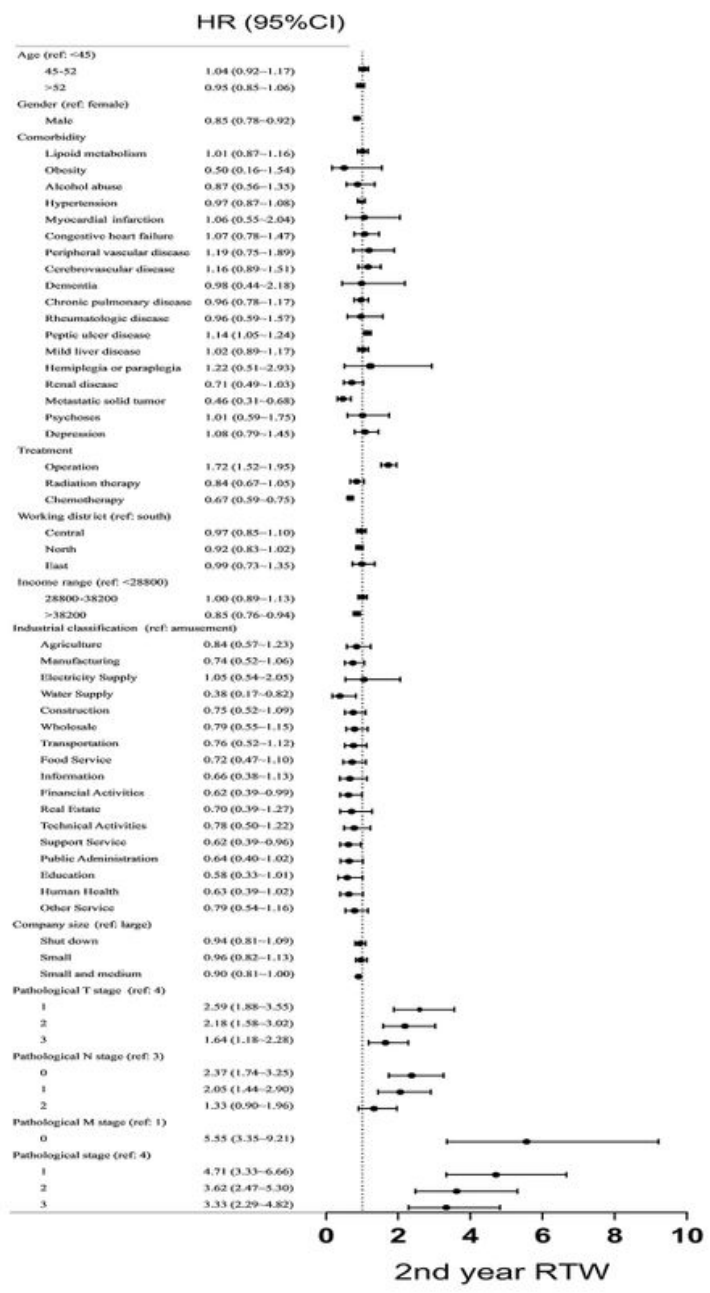

B

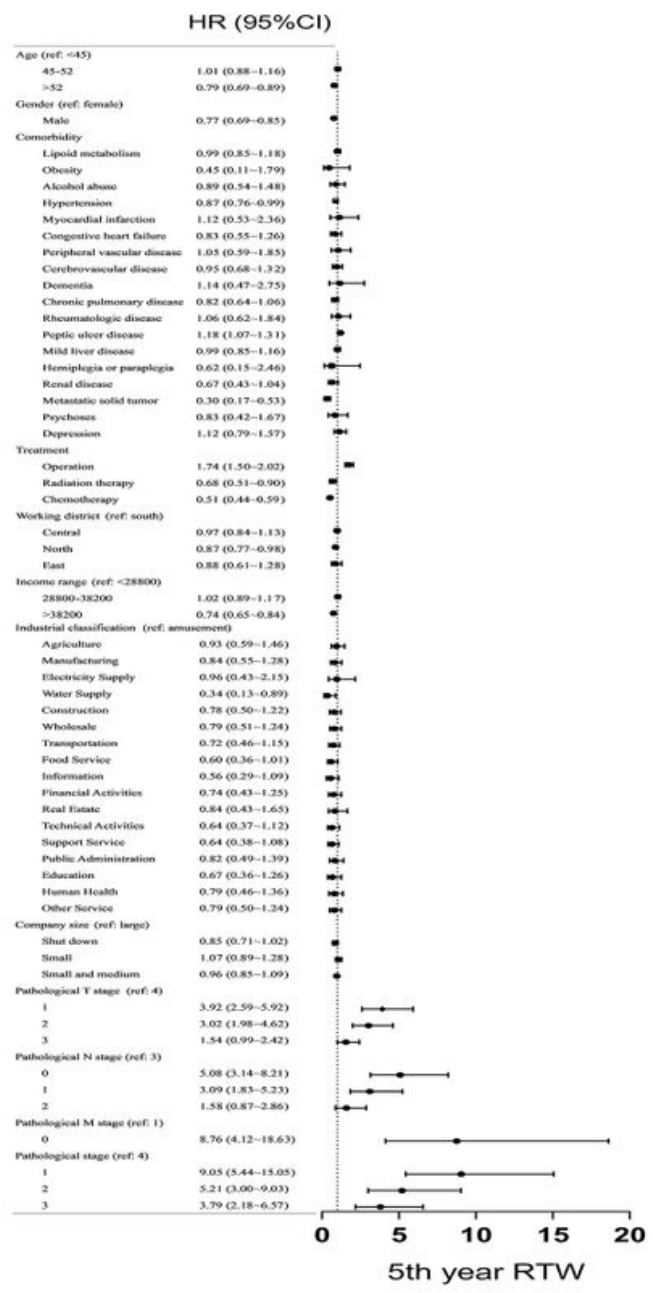

\section{Figure 1}

Univariate association between independent variables and RTW in the 2nd and 5th year 
A

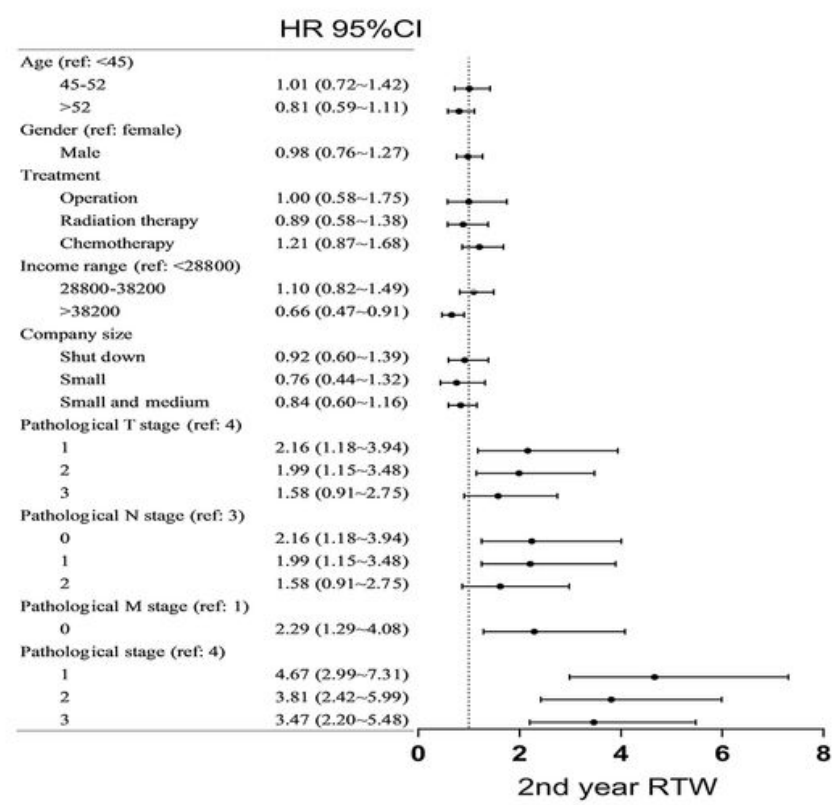

B

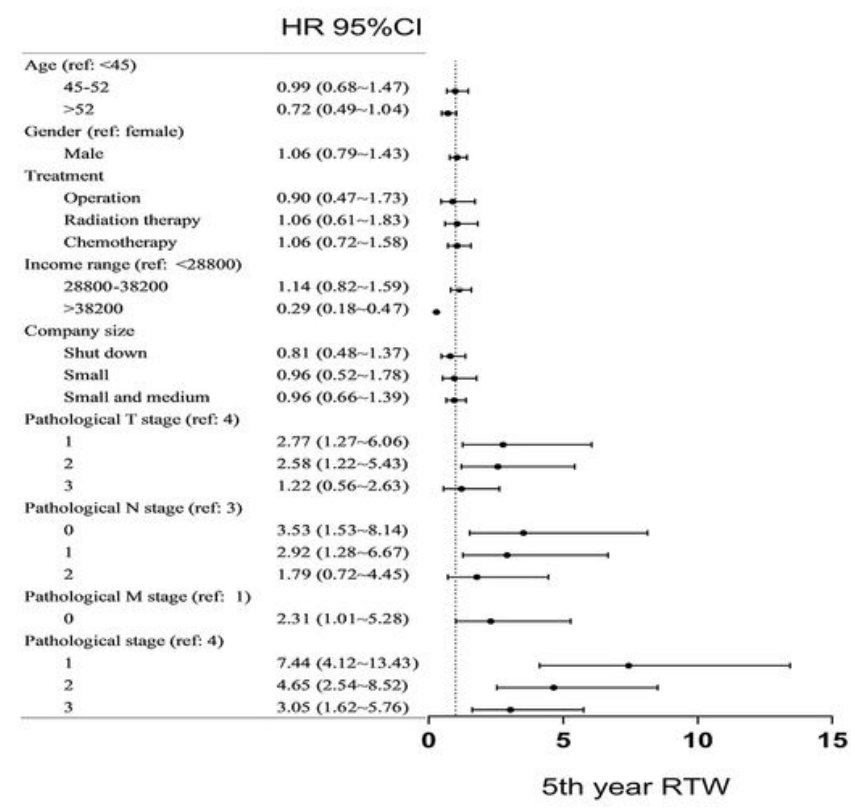

Figure 2

Multivariate association between independent variables and RTW in the 2nd and 5th year 

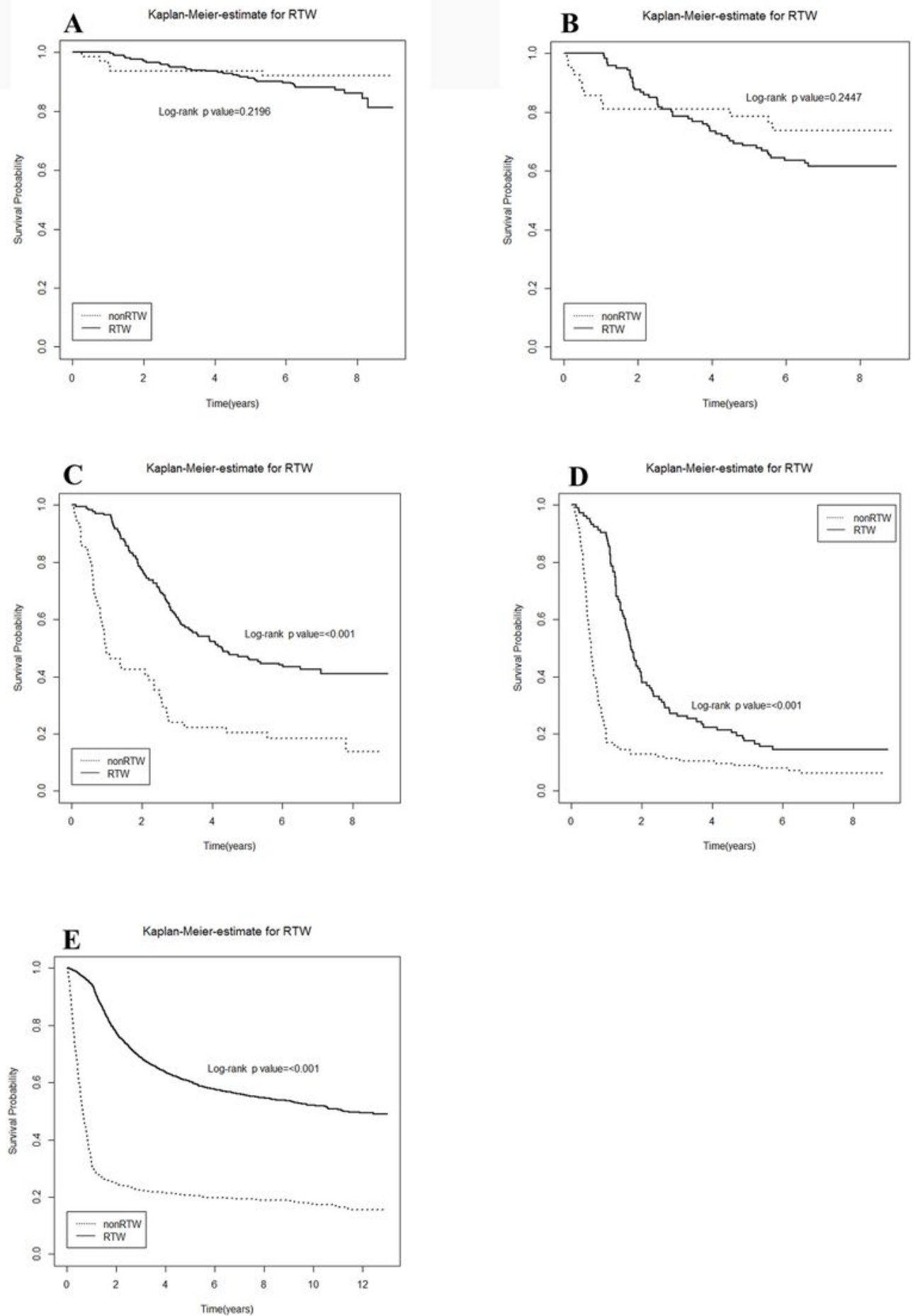

\section{Figure 3}

Kaplan-Meier curve for all-cause mortality categorized by different stages of gastric cancer (A) all stages;

(B) stage 1; (C) stage 2; (D) stage 3; (E) stage 4

\section{Supplementary Files}


This is a list of supplementary files associated with this preprint. Click to download.

- Supplementarymaterial.docx 